\title{
Twin domains of ScN (001) films on MgO (001)
}

\author{
E. de Prado, J. More-Chevalier, S. Cichoň, J. Lančok \\ Institute of Physics of the Czech Academy of Sciences, Na Slovance 2, 18221 Praha 8, Czechia
}

prado@fzu.cz

Scandium nitride $(\mathrm{ScN})$ has attracted a great deal of attention in recent years due to its promising properties as high hardness, temperature stability and high electrical conductivity [1], [2]. Twin domains have been already studied in this interesting material for some other configurations including $\mathrm{ScN}$ crystalline and polycrystalline growth on different substrates[3]-[5]. Five epitaxial (001) $\mathrm{ScN}$ films from $145 \mathrm{~nm}$ to $1080 \mathrm{~nm}$ thicknesses were deposited at the same conditions on $\mathrm{MgO}(001)$ substrate by DC reactive magnetron sputtering. The presence of twins has been analyzed through 2 theta scans, 002,022 and 111 pole figures and 2D reciprocal space maps (RSM). Four twin domains are present in all samples being (111) the twining plane. This gives rise to twelve distinguished peaks of 002 reflection (labelled on the inset pole figure for the thickest sample in Figure 1). Special care must be taken for thinner samples, since the presence of twins can be hidden under the strong contribution arisen from the epitaxial layer. The twins/epitaxial layer diffracted intensity ratio seems to rise with the layer thickness. Further research must be done to elucidate if there is a limiting layer thickness for twin formation.

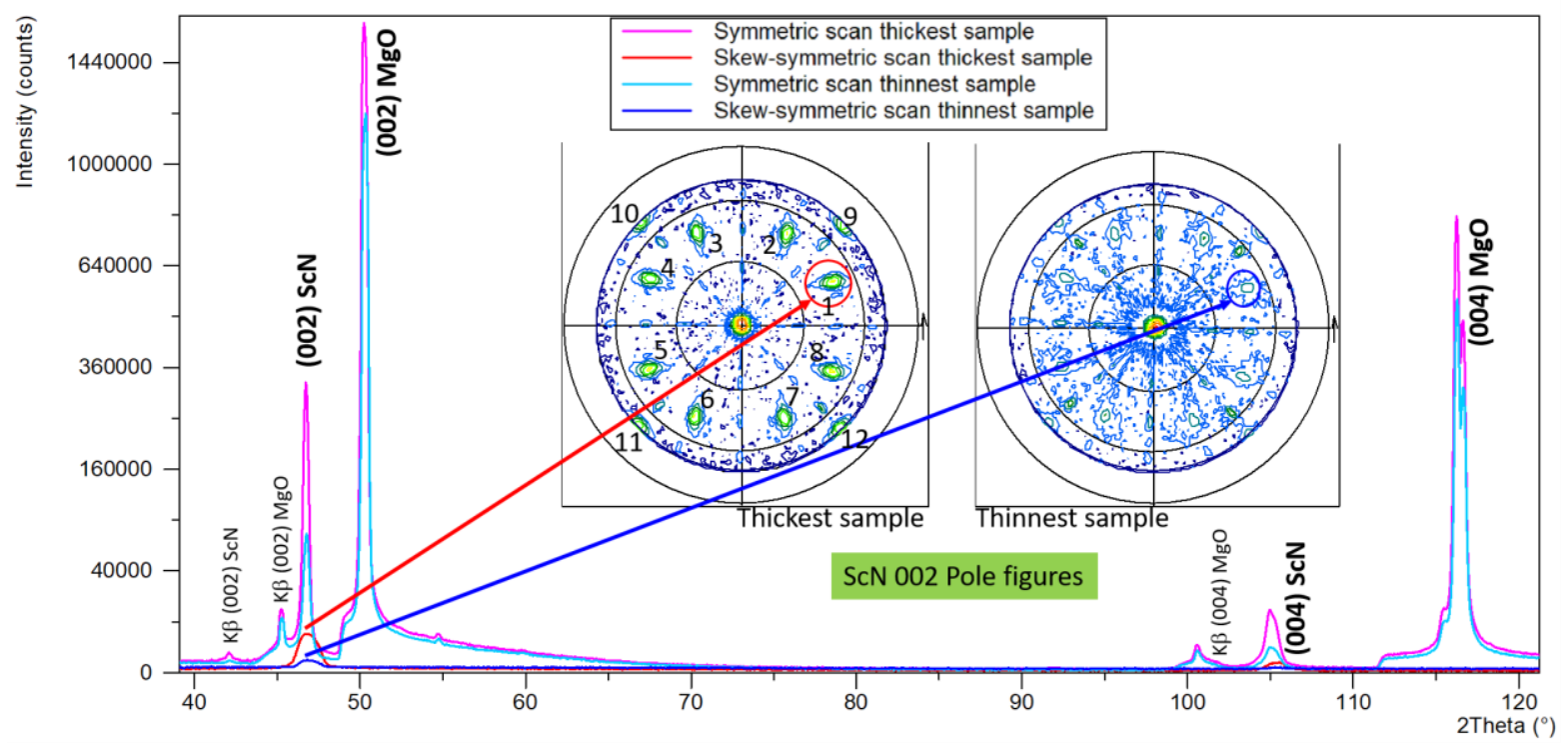

Figure 1. 2theta scans for the thickest and thinnest layers. Symmetric (pink and light blue) and skew-symmetric (red and dark blue) which are performed at the phi/chi angle corresponding to the peak coming from the twins labelled as 1. Inset: 002 pole figures for both samples.

[1] Smith, A.R.; Al-Brithen, H.A.H.; Ingram, D.C.; Gall, D. (2001). J. Appl. Phys. 90 1809-1816

[2] Gall, D.; Petrov, I.; Hellgren, N.; Hultman, L.; Sundgren, J.E.; Greene, J.E. (1998). J. Appl. Phys. 84 6034-6041

[3] More-Chevalier, J.; Cichoň, S.; Horák, L.; Buliřr, J.; Hubík, P.; Gedeonová, Z.; Fekete, L.; Poupon, M.; Lančok, J. (2020). Appl. Surf. Sci. 515 145968

[4] Moram, M.A.; Joyce, T.B.; Chalker, P.R.; Barber, Z.H.; Humphreys, C.J. (2006). Appl. Surf. Sci. $2528385-8387$

[5] Casamento, J.; Wright, J.; Chaudhuri, R.; Xing, H.G.; Jena, D. (2019). Appl. Phys. Lett. 115172101

\section{Keywords: ScN; twins; pole figure; epitaxial layer}

The authors would like to thank Czech Ministry of Education, Youth and Sports (SOLID21—CZ.02.1.01/0.0/0.0/16_019/0000760) 